\title{
A Rare Histopathological Phenotype of Primary Central Nervous System Lymphoma
}

Zara loannides ${ }^{1 *}$, Monica S Badve ${ }^{1}$, Queenie Lau ${ }^{2}$ and Sandeep Bhuta ${ }^{3}$

${ }^{1}$ Department of Neurology, Gold Coast University Hospital, Queensland, 4215, Australia ${ }^{2}$ Department of Pathology, Gold Coast University Hospital, Queensland, 4215, Australia

${ }^{3}$ Department of Medical Imaging, Gold Coast University Hospital, Queensland, 4215, Australia

\section{Case Summary}

A 42-year old male presented with a new generalised severe dull aching headache, vomiting, and bilateral papilloedema. MRI brain revealed a mass lesion cuffing the lateral ventricles (Figure 1). He developed pyramidal tract signs, cerebellar dysfunction, aphasia and seizures. Laboratory testing was negative for human immunodeficiency virus serology and bone marrow biopsy was unremarkable. Brain biopsy showed a blastichematolymphoid malignancy (Figure 2). Imaging for evidence of systemic disease outside the central nervous system was negative. Intravenous corticosteroids were administered but the patient deteriorated and his family opted for palliation. He died four weeks after his initial presentation.

\section{Discussion}

Primary CNS Lymphoma (PCL) is an aggressive disease, most commonly occurring in immunosuppressed individuals, particularly in the context of HIV infection. PCL can involve the brain, meninges, eyes or spinal cord [1,2]. Brain involvement, known as primary cerebral lymphoma, may manifest as solitary or multiple intracranial lesions, or as diffuse leptomeningeal or periventricular lesions. Periventricular lesions in the brain present with heterogeneous features including headache, focal neurological deficits, personality changes, raised intracranial pressure and seizures. Approximately $98 \%$ of PCL are CD20+ B-cell lymphomas, usually of the diffuse large-cell, immunoblastic, or lymphoblastic subtypes [3]. This case is unusual as it occurred in a seemingly immunocompetent individual and followed an aggressive clinical course. Furthermore, biopsy (Figure 2) revealed a
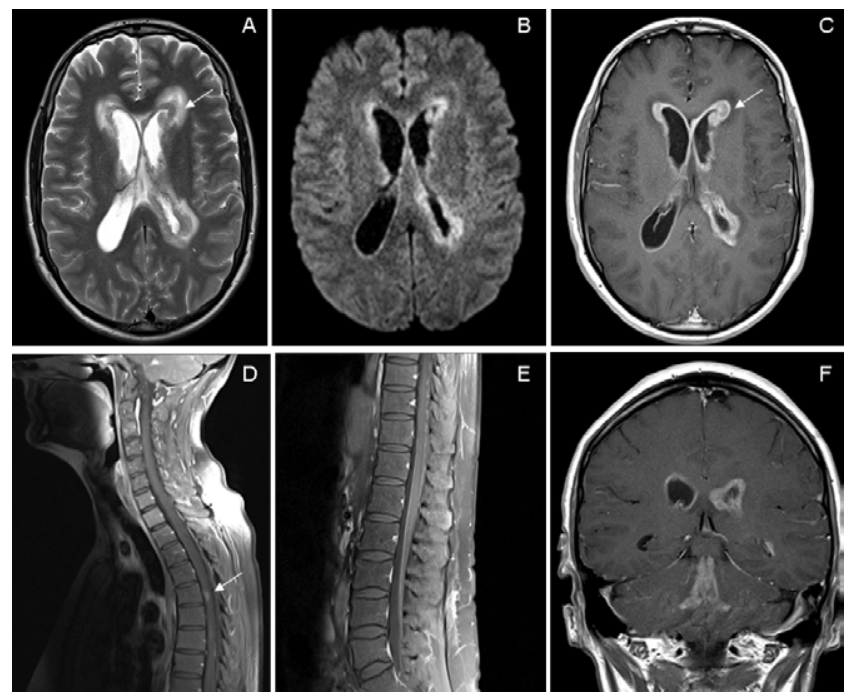

T2 weighted axial image demonstrates periventricular mass ( $A$, arrow) with restricted diffusion (B). Periventricular enhancement and leptomeningeal enhancement seen in the brain and spinal cord (C-F).

Figure 1: MRI brain and spine with contrast.

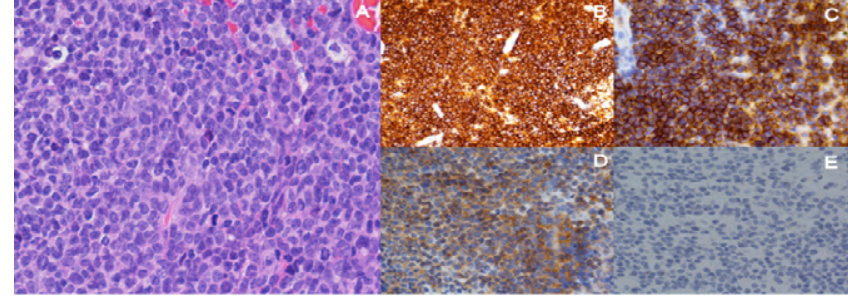

(A) Monomorphousblastichematolymphoid infiltrate (Haematoxi and eosin 400x). Immunohistochemistry demonstrates immunoreactivity of tumour cells for (B) CD43, (C) CD56 and (D) CD4.(E) CD123 is negative.

Figure 2: Brain biopsy.

rare non-B cell lineage with an unusual immunophenotype suggesting a blastic hematolymphoid malignancy, which was not lineage specific and may be seen in T cell lymphoma, Natural Killer cell lymphoma, or myeloid sarcoma.

Some cases of PCL respond to methotrexate based chemotherapy and radiotherapy, however, treatment is rarely curative. This case demonstrates a characteristic presentation and MRI features of primary CNSlymphoma. However, it is unusual due to atypical immunohistology, (non-B cell origin), absence of apparent immunodeficiency and rapid deterioration leading to death within one month.

\section{Author Contributions}

MSB conceptualised the report, ZI drafted the report and prepared the manuscript, QL prepared the pathology slides and revised the draft, SB supervised the imaging and revised the draft.

\section{References}

1. Gerstner E, Batchelor T (2007) Primary CNS lymphoma. Expert Rev Anticancer Ther 7: 689-700.

2. Hattab EM, Martin SE, Al-Khatib SM, Kupsky WJ, Vance GH, et al. (2010) Most primary central nervous system diffuse large B-cell lymphomas occurring in immunocompetent individuals belong to the nongerminalcenter subtype: a retrospective analysis of 31 cases. Mod Pathol 23: 235-243.

3. Nakamura M, Shimada K, Ishida E, Konishi N (2004) Histopathology, pathogenesis and molecular genetics in primary central nervous system lymphomas. HistolHistopathol 19: 211-219.

*Corresponding author: Zara A loannides, Gold Coast University Hospital, Ward C5W, 1 Hospital Boulevard, Southport, 4215, Queensland, Australia, Tel: +61405270009; E-mail: z.ioannides@gmail.com

Received February 20, 2014; Accepted February 24, 2014; Published March 03, 2014

Citation: loannides Z, Badve MS, Lau Q, Bhuta S (2014) A Rare Histopathologica Phenotype of Primary Central Nervous System Lymphoma. J Integr Oncol 3: 112 doi:10.4172/2329-6771.1000112

Copyright: (c) 2014 loannides Z, et al. This is an open-access article distributed under the terms of the Creative Commons Attribution License, which permits unrestricted use, distribution, and reproduction in any medium, provided the original author and source are credited. 